\title{
Effective Reduction of Inflammatory and Coagulation Factors using Sitagliptin in Type 2 Diabetes
}

\author{
Maryam Ghavami ${ }^{1}$, Jalil Houshyar², Amir Mehdizadeh², Mostafa Najafipour ${ }^{3,4}$ and Farzad Najafipour ${ }^{2,5, *}$ \\ 1 Department of Internal Medicine, Endocrinology Division, School of Medicine, Ardabil University of Medical Sciences, Ardabil, Iran \\ 2 Endocrine Research Center, Tabriz University of Medical Sciences, Tabriz, Iran \\ 3 Young Researchers and Elite Club, Ardabil Branch, Islamic Azad University, Ardabil, Iran \\ 4 Department of Internal Medicine, Faculty of Medicine, Ardabil Azad University of Medical Sciences, Ardabil, Iran \\ ${ }^{5}$ Imam Reza Hospital, Tabriz University of Medical Sciences, Tabriz, Iran
}

* Corresponding author: Farzad Najafipour, Endocrine Research Center, Tabriz University of Medical Sciences, Tabriz, Iran. Email: farzadnajafipour@gmail.com

Received 2020 December 29; Revised 2021 January 13; Accepted 2021 February 18

\begin{abstract}
Background: There are different drug-based treatments (i.e., oral or injective) for patients with type 2 diabetes. Pioglitazone and sitagliptin, among oral agents, can affect blood glucose control and lipid profile.

Objectives: The purpose of the current investigation was the assessment of the effects of adding sitagliptin or pioglitazone (as the third drug) to the combined metformin-sulfonylurea treatment on glycemic control, inflammatory factors, and lipid profile.

Methods: This clinical trial was carried out on 125 patients with type 2 diabetes undergoing metformin-glibenclamide treatment. The patients were randomly divided into three groups, namely the sitagliptin group receiving $100 \mathrm{mg}$ of sitagliptin for $3 \mathrm{months}$ ( $\mathrm{n}=45$ ), pioglitazone group receiving $30 \mathrm{mg}$ of pioglitazone for 3 months $(\mathrm{n}=40)$, and control group $(\mathrm{n}=40)$. After the interventions, the anthropometric indices, glycated hemoglobin A1c level, lipid profile, fibrinogen, and high-sensitivity C-reactive protein (hs-CRP) were compared among the study groups.

Results: The sitagliptin group demonstrated significantly lower levels of hs-CRP $(0.53 \pm 0.26 \mathrm{mg} / \mathrm{L})$ and fibrinogen $(314.08 \pm 48.09$ $\mathrm{mg} / \mathrm{dL}$ ), compared to those reported for the pioglitazone and control groups. In contrast, significantly lower triglyceride levels $(115.02 \pm 32.92 \mathrm{mg} / \mathrm{dL})$ and significantly higher high-density lipoprotein cholesterol $(51.57 \pm 11.14 \mathrm{mg} / \mathrm{dL})$ were observed in the pioglitazone group in comparison to those reported for the sitagliptin and control groups.

Conclusion: The results of the present study suggest that sitagliptin reduces the levels of fibrinogen and hs-CRP. Nevertheless, pioglitazone has a more significant effect on the improvement of the lipid profile, compared to sitagliptin and combined metformin-sulfonylurea treatments.
\end{abstract}

Keywords: Fibrinogen, hs-CRP, Pioglitazone, Sitagliptin, Type 2 diabetes

\section{Background}

Type 2 diabetes mellitus is regarded as a chronic metabolic disease, with the progressive impairment of insulin sensitivity and $\beta$-cell function as its characteristics, leading to hyperglycemia (1). Although no definitive therapeutic strategy has been developed for the improvement of the $\beta$-cell function, anti-diabetic agents can reduce the progressive insufficiency rate of these cells through their mechanisms of action (2). Thiazolidinediones are a group of anti-diabetic agents, which increase insulin sensitivity in the liver, causing reduced hepatic glucose production and insulin resistance in the peripheral tissues. These drugs, including pioglitazone, improve insulin resistance through the activation of peroxisome proliferator-activated receptor- $\gamma$ in the liver and adipose tissues $(3,4)$. Pioglitazone can also improve the lipid profile, liver function, blood pressure, and body weight (5-7).

Dipeptidyl peptidase-4 (DPP4) inhibitors, such as sitagliptin, are other anti-diabetic agents, which increase the incretin hormone activity, leading to the improved secretion of insulin and suppressed secretion of pancreatic glucagon (8). Owing to their considerable anti-diabetic properties and few side effects, these agents are routinely administered around the world. It has been reported that sitagliptin, as one of the members of this family, improves glycemic control and lipid profile and reduces blood pressure and body weight (9-12). However, few studies have compared the effectiveness of DPP-4 inhibitors (e.g., sitagliptin) to other drug categories (e.g., thiazolidinediones) (13-15).

Some studies have reported a similar or better glycemic control with DPP-4 inhibitors, compared to that reported for thiazolidinediones. However, the results of a study carried out on the effects of sulfonylureas, thiazolidinediones, and DPP-4 inhibitors in combination with metformin showed that thiazolidinediones exert long-term effects (16). In addition, the findings of another study indicated that some patients undergoing combined metforminsulfonylurea therapy may not achieve the desired glycemic control and a third drug may be needed (7).

\section{Objectives}

Due to the limited number of studies evaluating the effects of three-drug combination therapies on 
glycemic control, the purpose of the current study was to compare the effects of adding sitagliptin or pioglitazone to combined metformin-sulfonylurea treatment on the inflammatory markers, coagulation factors, and lipid profile of patients with diabetes.

\section{Methods}

This clinical trial (code: IRCT201306100 13612N9) was performed on 125 patients with type 2 diabetes undergoing metformin (1000 mg) and glibenclamide $(15 \mathrm{mg}$ ) treatment referring to the endocrinology clinics of Imam Reza Hospital, affiliated to Tabriz University of Medical Sciences, Tabriz, Iran. The sample size was calculated using G*Power software (version 3.1.9.2; Düsseldorf, Germany). In this study, 40-45 patients were randomly divided into three groups $(\alpha=0.05$, power $=0.8$, and effect size $=0.5$ ), namely sitagliptin group receiving $100 \mathrm{mg}$ of sitagliptin ( $\mathrm{n}=45)$, pioglitazone group receiving $30 \mathrm{mg}$ of pioglitazone $(n=40)$, and control group $(n=40)$. The drugs were added to the primary treatment for a course of 3 months.

The inclusion criteria were a diagnosis of type 2 diabetes, age range of 45-70 years, glycated hemoglobin A1c (HbA1c) level of $7-8 \%$, and body mass index (BMI) of $20-35 \mathrm{~kg} / \mathrm{m}^{2}$. On the other hand, the exclusion criteria were hospitalization due to hyperglycemia, irregular medication consumption, lack of regular visits, cardiovascular and autoimmune diseases, pregnancy, warfarin consumption, infection, history of malignancy, history of chronic lung disease, glomerular filtration rate of $<60 \mathrm{ml} / \mathrm{min} / 1.73 \mathrm{~m}^{2}$, and unwillingness to participate in the study.

After 3 months of intervention, fasting blood sugar (FBS), HbA1c, high-sensitivity C-reactive protein (hs-CRP), fibrinogen, and lipid profile (including triglyceride, cholesterol, high-density lipoprotein cholesterol [HDL-C], and low-density lipoprotein cholesterol [LDL-C] levels) were evaluated. Figure 1 depicts the flow diagram of the study subjects. Written informed consent was

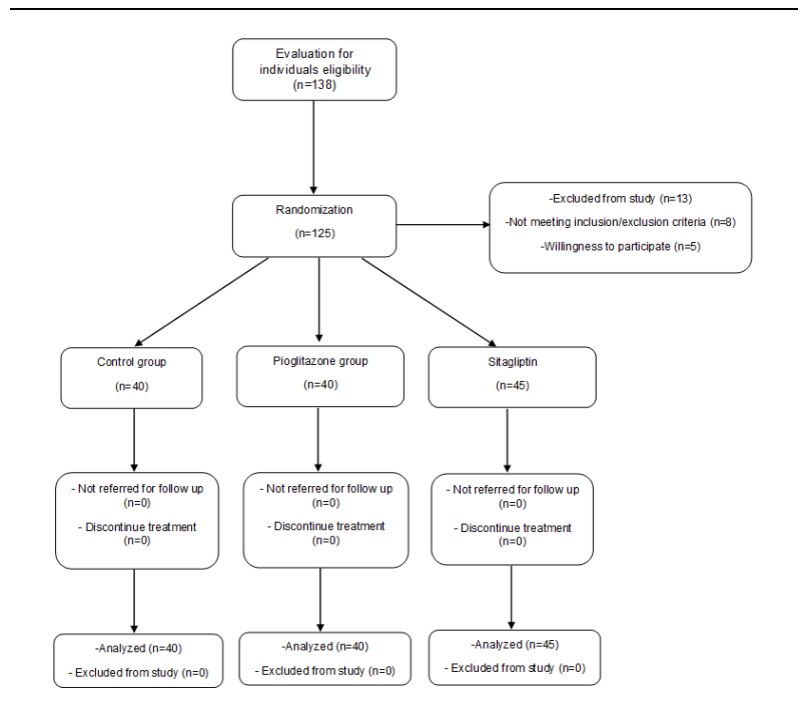

Figure 1. Flow diagram of the study patients

obtained from the patients prior to the intervention. Furthermore, the ethical approval of the present study was obtained by the Ethics Committee of Tabriz University of Medical Sciences (code: IR.TBZMED. REC.REC.1397.102).

\subsection{Statistical analysis}

SPSS software (version 23) was used in order to analyze the data. One-way analysis of variance and post hoc analysis were utilized for the comparisons between the groups. A p-value of less than 0.05 was regarded as statistically significant.

\section{Results}

\subsection{General characteristics and biochemical parameters of patients}

Table 1 tabulates the general characteristics and biochemical parameters of 125 diabetic patients (including 49 male and 76 female patients). The mean values of the patients' age in the sitagliptin, pioglitazone, and control groups were reported as $59.48 \pm 12.15,58.9 \pm 9.94$, and $55.8 \pm 8.97$ years,

\begin{tabular}{|c|c|c|c|c|c|}
\hline Parame & & $\begin{array}{c}\text { Sitagliptin } \\
(n=45)\end{array}$ & $\begin{array}{c}\text { Pioglitazone } \\
(n=40)\end{array}$ & $\begin{array}{l}\text { Control } \\
(n=40)\end{array}$ & P-value \\
\hline \multirow{2}{*}{ Gender } & Male n (\%) & $20(44.4)$ & $17(42.5)$ & $12(30)$ & \multirow{2}{*}{0.34} \\
\hline & Female n (\%) & $25(55.6)$ & $23(57.5)$ & $28(70)$ & \\
\hline \multicolumn{2}{|c|}{ Age (year) } & $59.48 \pm 12.15^{*}$ & $58.9 \pm 9.94$ & $55.8 \pm 8.97$ & 0.23 \\
\hline \multicolumn{2}{|c|}{$\mathrm{BMI}\left(\mathrm{Kg} / \mathrm{m}^{2}\right)$} & $30.44 \pm 5.79$ & $30.02 \pm 5.02$ & $29.08 \pm 4.81$ & 0.73 \\
\hline \multicolumn{2}{|c|}{ FBS (mg/dL) } & $143.33 \pm 52.99$ & $131.12 \pm 35.27$ & $143.33 \pm 52.99$ & 0.43 \\
\hline \multicolumn{2}{|c|}{ HbA1c (\%) } & $7.26 \pm 1.6$ & $7.46 \pm 1.4$ & $7.36 \pm 0.9$ & 0.67 \\
\hline \multicolumn{2}{|c|}{ Triglyceride (mg/dL) } & $159.53 \pm 66.83^{a}$ & $115.02 \pm 32.92^{b}$ & $171.79 .76^{\mathrm{a}}$ & $<0.001$ \\
\hline \multicolumn{2}{|c|}{ Cholesterol (mg/dL) } & $154.06 \pm 39.61$ & $149.1 \pm 33.31$ & $158.95 \pm 34.26$ & 0.47 \\
\hline \multicolumn{2}{|c|}{ HDL-C (mg/dL) } & $41.51 \pm 7.71^{\mathrm{a}}$ & $51.57 \pm 11.14^{b}$ & $44.18 \pm 11.09^{a}$ & $<0.001$ \\
\hline \multicolumn{2}{|c|}{ LDL-C (mg/dL) } & $80.64 \pm 34.51$ & $74.52 \pm 32.32$ & $80.42 \pm 29.25$ & 0.62 \\
\hline
\end{tabular}




\begin{tabular}{|c|c|c|c|c|}
\hline Parameter & $\begin{array}{c}\text { Sitagliptin } \\
(n=45)\end{array}$ & $\begin{array}{c}\text { Pioglitazone } \\
(n=40)\end{array}$ & $\begin{array}{l}\text { Control } \\
(n=40)\end{array}$ & P-value \\
\hline hs-CRP (mg/L) & $0.53 \pm 0.26^{\mathrm{a}}$ & $2.44 \pm 0.52^{\mathrm{b}}$ & $4.43 \pm 1.94^{\mathrm{b}}$ & 0.04 \\
\hline Fibrinogen (mg/dL) & $314.08 \pm 48.09^{a}$ & $340.92 \pm 65.1^{b}$ & $346.35 \pm 60.69^{b}$ & 0.02 \\
\hline
\end{tabular}

respectively $\quad(\mathrm{P}=0.23)$. A significantly lower triglyceride level $\quad(115.02 \pm 32.92 \mathrm{mg} / \mathrm{dL} \quad$ vs. $159.53 \pm 66.83$ and $171.79 .76 \mathrm{mg} / \mathrm{dL} ; \mathrm{P}=0.002$ and $\mathrm{P}<0.001$, respectively) and higher HDL-C level $(51.57 \pm 11.14 \mathrm{mg} / \mathrm{dL}$ vs. $41.51 \pm 7.71$ and $44.18 \pm 11.09$ $\mathrm{mg} / \mathrm{dL} ; \mathrm{P}<0.001$ and $\mathrm{P}=0.001$, respectively) were observed in the pioglitazone group, compared to those reported for the sitagliptin and control groups.

There were no significant differences in BMI $\left(30.44 \pm 5.79, \quad 30.02 \pm 5.02\right.$, and $29.08 \pm 4.81 \mathrm{~kg} / \mathrm{m}^{2}$, respectively; $\mathrm{P}=0.73)$, FBS $(143.33 \pm 52.99,131.12 \pm$ 35.27 , and $143.33 \pm 52.99 \mathrm{mg} / \mathrm{dL}$, respectively; $\mathrm{P}=0.43)$, HbA1c (7.26 $\pm 1.6 \%, 7.46 \pm 1.4 \%$, and $7.36 \pm 0.9 \%$, respectively; $\mathrm{P}=0.67)$, cholesterol $(154.06 \pm 39.61$, $149.1 \pm 33.31$, and $158.95 \pm 34.26 \mathrm{mg} / \mathrm{dL}$, respectively; $\mathrm{P}=0.47)$, and LDL-C $(80.64 \pm 34.51,74.52 \pm 32.32$, and $80.42 \pm 29.25 \mathrm{mg} / \mathrm{dL}$, respectively; $\mathrm{P}=0.62$ ) among the sitagliptin, pioglitazone, and control groups.

\section{2. hs-CRP and fibrinogen measurements}

Table 2 shows the levels of hs-CRP and fibrinogen in the three groups under study. The sitagliptin group showed a significantly lower hs-CRP level, compared to the pioglitazone and control groups $(0.53 \pm 0.26 \mathrm{mg} / \mathrm{L}$ vs. $2.44 \pm 0.52$ and $4.43 \pm 1.94 \mathrm{mg} / \mathrm{L}$, respectively; $\mathrm{P}<0.001$ ); however, there was no significant difference between the pioglitazone and control groups in this regard $(\mathrm{P}=0.25)$. Moreover, the sitagliptin group demonstrated a significantly lower fibrinogen level in comparison to the pioglitazone and control groups $(314.08 \pm 48.09 \mathrm{mg} / \mathrm{dL}$ vs. $340.92 \pm 65.1$ and $346.35 \pm 60.69 \mathrm{mg} / \mathrm{dL} ; \mathrm{P}=0.03$ and $\mathrm{P}=0.01$, respectively). No noticeable difference was observed between the pioglitazone and control groups regarding the fibrinogen level $(\mathrm{P}=0.67)$.

\section{Discussion}

Metformin is known as the first-line therapeutic agent for diabetes. Thiazolidinediones, such as pioglitazone, have been reported to be effective in different aspects of insulin resistance in diabetic patients, including dyslipidemia, hyperglycemia, hypertension, cardiovascular diseases, coagulation, vasculopathy, facilitated atherosclerosis, and hepatic or ovarian changes $(17,18)$. On the other hand, the beneficial effects of DPP-4 inhibitors, such as sitagliptin, on glycemic control are well-documented in single-drug or combination treatments with other therapeutic agents (19). However, these drug categories may have side effects, such as edema and weight gain.

In the current investigation, the effects of adding sitagliptin and pioglitazone to the metforminsulfonylurea treatment of patients with inadequate glycemic control showed that both drugs could improve the HbA1c level; nevertheless, this improvement was not statistically significant. Similarly, Khaloo et al. (7) reported that sitagliptin and pioglitazone had similar effects on the level of HbA1c. Jameshorani et al. (20) also reported the similar effects of sitagliptin and pioglitazone in combination with metformin on the improvement of HbA1c. In addition, Liu et al. (13) indicated the effectiveness of sitagliptin and pioglitazone in the reduction of HbA1c level; nonetheless, a greater FBS reduction was observed in response to pioglitazone, compared to that reported for sitagliptin.

Furthermore, the beneficial effects of sitagliptin and pioglitazone on the lipid profile are wellestablished. It has been reported that sitagliptin affects all the components of the lipid profile $(21,22)$. A recent meta-analysis demonstrated the improving effect of sitagliptin on triglyceride and HDL levels, especially in combination with other drugs (23). The findings of the present study also revealed a significant decrease in triglyceride and HDL following pioglitazone addition to the dual drug treatment, compared to those reported for the sitagliptin and control groups; however, there was no significant difference in cholesterol and LDL levels between the groups. Similar results have been reported by Li et al. (13).

Generally, one of the main disadvantages of pioglitazone is the patient's overweight during the treatment $(21,24)$. In this regard, a study carried out by Liu et al. (13) reported significant weight gain after pioglitazone use in comparison to that of sitagliptin. In the current study, the patients' weight was not measured prior to the drug intervention; however, there was no significant difference regarding the weight or BMI among the study groups.

There is a common association between diabetes mellitus and increased level of inflammatory markers, including C-reactive protein (CRP) and hsCRP (25). In a previous study, a significant correlation was observed between the increased level of hs-CRP and history of atherosclerosis; therefore, the increased level of hs-CRP was regarded as a risk factor for cardiovascular diseases (26).

The findings of the present study demonstrated a significant reduction in the hs-CRP level in the 
sitagliptin group in comparison to those reported for the pioglitazone and control groups. Furthermore, a study conducted by Umamahewari et al. (27) reported that sitagliptin causes a remarkable reduction in the level of CRP. Similarly, Sato-Asahara et al. (28) indicated a significant reduction in the levels of CRP and tumor necrosis factor-alpha in type 2 diabetic individuals after sitagliptin use.

Although the results of a recent meta-analysis indicated the effectiveness of DPP-4 inhibitors in the CRP level, none of them were as effective as other anti-diabetic agents (29). Some studies have also shown the beneficial effects of pioglitazone on the levels of CRP and hs-CRP. In this regard, Chen et al. (30) and Park et al. (31) reported decreased CRP levels following pioglitazone use. Another study carried out by Liu et al. (13) reported a decreased CRP level following pioglitazone administration, despite an increased CRP level after sitagliptin use. However, Kim et al. (32) demonstrated no significant difference in the inflammatory markers, including hsCRP, after the administration of vildagliptin and pioglitazone.

Considering the fact that fibrinogen is a coagulation factor, the results of the present study showed that sitagliptin significantly decreased the level of this glycoprotein, compared to the pioglitazone and control groups. In contrast, pioglitazone caused no significant changes in the fibrinogen level. Paschalidou et al. also reported similar results (33). On the other hand, in studies conducted by Pfutzner et al. (34) and Derosa et al. (35), it was shown that pioglitazone and rosiglitazone had no significant effects on the levels of fibrinogen and tissue-type plasminogen activator. However, Khan et al. (33) reported that pioglitazone could further decrease the fibrinogen level in comparison to vildagliptin. The discrepancy between different studies may be the result of inadequate sample size, ethnic differences, diabetes duration, use of single or multi-drug treatments, and therapy duration. In general, pioglitazone, as an adjuvant for dual-drug treatments, seems to have acceptable effects and is also well-tolerated by diabetic patients.

\section{Conclusion}

Based on the findings of the present study, sitagliptin decreased the levels of fibrinogen and hsCRP; however, pioglitazone had a significant effect on the lipid profile, compared to the dual-drug (metformin plus sulfonylurea) and sitagliptin treatments. According to the current results, the use of sitagliptin and pioglitazone is recommended in three-drug treatments for glycemic and lipid profile control. Considering the scarcity of research and contradictory findings regarding the effects of pioglitazone and sitagliptin on weight, HbA1c, FBS, lipid profile, CRP, and fibrinogen, it is suggested to carry out further investigations with a larger sample size, assessing laboratory and anthropometric indices before and after interventions to determine the exact effectiveness of these therapies.

\section{Acknowledgments}

This work was performed as a part of a dissertation on endocrinology subspecialty by Maryam Ghavami. This study was supported by Endocrine Research Center at Tabriz University of Medical Sciences, Tabriz, Iran. The authors would like to express their gratitude to Endocrine Research Center and Department of Internal Medicine at Tabriz University of Medical Sciences for their great assistance.

\section{Footnotes}

Authors' Contribution: Dr. Farzad Najafipour designed and directed the whole project. Dr. Maryam Ghavami carried out the experiments. Dr. Jalil Houshyar and Dr. Mostafa Najafipour wrote the manuscript with support from Dr. Farzad Najafipour who analyzed the data. Dr. Maryam Ghavami contributed to sample preparation. All the authors discussed the results and contributed to the final manuscript.

Conflict of Interests: The authors declare that there is no conflict of interest.

Ethical Approval: This study was approved by the Ethics Committee of Tabriz University of Medical Sciences (code: IR.TBZMED.REC.REC.1397.102). The current study was performed in accordance with the Declaration of Helsinki and good clinical practice principles.

Funding/Support: This study was supported by a grant from Endocrine Research Center, Tabriz University of Medical Sciences.

Informed Consent: Verbal and written informed consent was obtained from all the participants.

\section{References}

1. Petersen MC, Shulman GI. Mechanisms of insulin action and insulin resistance. Physiol Rev. 2018;98(4):2133-223. doi: 10.1152/physrev.00063.2017. [PubMed: 30067154].

2. Samtani MN. Simple pharmacometric tools for oral anti-diabetic drug development: competitive landscape for oral non-insulin therapies in type 2 diabetes. Biopharm Drug Dispos. 2010;31(2-3):162-77. doi: 10.1002/bdd.700. [PubMed: 20213855].

3. Nanjan M, Mohammed M, Kumar BP, Chandrasekar M. Thiazolidinediones as antidiabetic agents: a critical review. Bioorg Chem. 2018;77:548-67. doi: 10.1016/j.bioorg.2018. 02.009. [PubMed: 29475164].

4. Yasmin S, Jayaprakash V. Thiazolidinediones and PPAR orchestra as antidiabetic agents: From past to present. Eur J Med Chem. 2017;126:879-93. doi: 10.1016/j.ejmech.2016.12.020. [PubMed: 27988463].

5. Al-Azzam SI, AlOmari M, Khader YS, AlMahasneh FA, Muflih 
SM, Altawalbeh S. Effects of pioglitazone add-on to gliclazide and metformin on glycemic control in patients with type 2 diabetes. Endocr Res. 2012;37(1):7-11. doi: 10.3109/07 435800.2011.566238. [PubMed: 21977974].

6. Filipova E, Uzunova K, Kalinov $\mathrm{K}$, Vekov $\mathrm{T}$. Effects of pioglitazone therapy on blood parameters, weight and BMI: a meta-analysis. Diabetol Metab Syndr. 2017;9(1):90. doi: 10.1186/s13098-017-0290-5. [PubMed: 29163673].

7. Khaloo P, Komeleh SA, Alemi H, Mansournia M, Mohammadi A, Yadegar A, et al. Sitagliptin vs. pioglitazone as add-on treatments in patients with uncontrolled type 2 diabetes on the maximal dose of metformin plus sulfonylurea. J Endocrinol Invest. 2019;42(7):851-7. doi: 10.1007/s40618-018-0991-0. [PubMed: 30535871].

8. Scheen AJ. DPP-4 inhibitors in the management of type 2 diabetes: a critical review of head-to-head trials. Diabetes Metab. 2012;38(2):89-101. doi: 10.1016/j.diabet.2011.11.001. [PubMed: 22197148].

9. Ahrén B. Use of DPP-4 inhibitors in type 2 diabetes: focus on sitagliptin. Diabetes Metab Syndr Obes. 2010;3:31-41. doi: 10.2147/dmsott.s7327. [PubMed: 21437074].

10. Derosa G, Ragonesi PD, Fogari E, Cicero AFG, Bianchi L, Bonaventura A, et al. Sitagliptin added to previously taken antidiabetic agents on insulin resistance and lipid profile: a 2-year study evaluation. Fundam Clin Pharmacol. 2014; 28(2):221-9. doi: 10.1111/fcp.12001. [PubMed: 23039403].

11. Ba J, Han P, Yuan G, Mo Z, Pan C, Wu F, et al. Randomized trial assessing the safety and efficacy of sitagliptin in Chinese patients with type 2 diabetes mellitus inadequately controlled on sulfonylurea alone or combined with metformin. J Diabetes. 2017;9(7):667-76. doi: 10.1111/1753-0407.12456. [PubMed: 27502307].

12. Harashima SI, Ogura M, Tanaka D, Fukushima T, Wang Y, Koizumi $\mathrm{T}$, et al. Sitagliptin add-on to low dosage sulphonylureas: efficacy and safety of combination therapy on glycaemic control and insulin secretion capacity in type 2 diabetes. Int J Clin Pract. 2012;66(5):465-76. doi: 10.1111/j.1742-1241.2012.02903.x. [PubMed: 22512606].

13. Liu SC, Chien KL, Wang CH, Chen WC, Leung CH. Efficacy and safety of adding pioglitazone or sitagliptin to patients with type 2 diabetes insufficiently controlled with metformin and a sulfonylurea. Endocr Pract. 2013;19(6):980-8. doi: 10.4158/EP13148.OR. [PubMed: 23807528].

14. Takihata M, Nakamura A, Tajima K, Inazumi T, Komatsu Y, Tamura $\mathrm{H}$, et al. Comparative study of sitagliptin with pioglitazone in Japanese type 2 diabetic patients: the COMPASS randomized controlled trial. Diabetes Obes Metab. 2013; 15(5):455-62. doi: 10.1111/dom.12055. [PubMed: 23279373].

15. Chawla S, Kaushik N, Singh NP, Ghosh RK, Saxena A. Effect of addition of either sitagliptin or pioglitazone in patients with uncontrolled type 2 diabetes mellitus on metformin: a randomized controlled trial. J Pharmacol Pharmacother. 2013;4(1):27-32. doi: 10.4103/0976-500X.107656. [PubMed: 23662021].

16. Mamza J, Mehta R, Donnelly R, Idris I. Important differences in the durability of glycaemic response among second-line treatment options when added to metformin in type 2 diabetes: a retrospective cohort study. Ann Med. 2016;48(4):224-34. doi: 10.3109/07853890.2016.1157263. [PubMed: 26982210].

17. Filipova EP, Uzunova KH, Vekov TY. Comparative analysis of therapeutic efficiency and costs (experience in Bulgaria) of oral antidiabetic therapies based on glitazones and gliptins. Diabetol Metab Syndr. 2015;7(1):63. doi: 10.1186/s13098015-0059-7. [PubMed: 26288659].

18. Banerjee S. Pioglitazone safe, so safe. J Assoc Physicians India. 2012;60:62-6. [PubMed: 22715548].

19. Scheen AJ. The safety of gliptins: updated data in 2018. Expert Opin Drug Saf. 2018;17(4):387-405. doi: 10.1080/14740338. 2018.1444027. [PubMed: 29468916].

20. Jameshorani M, Sayari S, Kiahashemi N, Motamed N. Comparative study on adding pioglitazone or sitagliptin to patients with type 2 diabetes mellitus insufficiently controlled with metformin. Open Access Maced J Med Sci. 2017;5(7):955-
62. doi: 10.3889/oamjms.2017.193. [PubMed: 29362626]

21. Kutoh E. Differential effects of pioglitazone on metabolic parameters in newly diagnosed, drug-naive Japanese patients with type 2 diabetes with or without metabolic syndrome. Endocr Res. 2010;35(3):118-27. doi: 10.3109/0743580 1003762164. [PubMed: 20712426].

22. Erem C, Ozbas H, Nuhoglu I, Deger O, Civan N, Ersoz H. Comparison of effects of gliclazide, metformin and pioglitazone monotherapies on glycemic control and cardiovascular risk factors in patients with newly diagnosed uncontrolled type 2 diabetes mellitus. Exp Clin Endocrinol Diabetes. 2014; 122(05):295-302. doi: 10.1055/s-0034-1370989. [PubMed: 24710641].

23. Fan M, Li Y, Zhang S. Effects of sitagliptin on lipid profiles in patients with type 2 diabetes mellitus: a meta-analysis of randomized clinical trials. Medicine. 2016;95(2):e2386. doi: 10.1097/MD.0000000000002386. [PubMed: 26765417].

24. Aghamohammadzadeh N, Niafar M, Dalir Abdolahinia E, Najafipour F, Mohamadzadeh Gharebaghi S, Adabi K, et al. The effect of pioglitazone on weight, lipid profile and liver enzymes in type 2 diabetic patients. Ther Adv Endocrinol Metab. 2015;6(2):56-60. doi: 10.1177/2042018815574229. [PubMed: 25941563].

25. Zografou I, Sampanis C, Gkaliagkousi E, Iliadis F, Papageorgiou A, Doukelis P, et al. Effect of vildagliptin on hsCRP and arterial stiffness in patients with type 2 diabetes mellitus. Hormones. 2015;14(1):118-25. doi: 10.14310/horm.2002.1512. [PubMed: 25402372].

26. Shaheer AK, Tharayil JK, Krishna PW. A comparative study of high sensitivity C-reactive protein and metabolic variables in type 2 diabetes mellitus with and without nephropathy. J Clin Diagn Res. 2017;11(9):BC01-4. doi: 10.7860/JCDR/2017/ 30272.10528. [PubMed: 29207691].

27. Umamaheswari A. To compare the anti-inflammatory effect of oral hypoglycemic drugs in type 2 diabetes mellitus. [Masters Thesis]. Coimbatore, India: PSG Institue of Medical Sciences and Research; 2016.

28. Satoh-Asahara N, Sasaki Y, Wada H, Tochiya M, Iguchi A, Nakagawachi R, et al. A dipeptidyl peptidase-4 inhibitor, sitagliptin, exerts anti-inflammatory effects in type 2 diabetic patients. Metabolism. 2013;62(3):347-51. doi: 10.1016/j. metabol.2012.09.004. [PubMed: 23062489].

29. Liu X, Men P, Wang B, Cai G, Zhao Z. Effect of dipeptidylpeptidase-4 inhibitors on C-reactive protein in patients with type 2 diabetes: a systematic review and meta-analysis. Lipids Health Dis. 2019;18(1):144. doi: 10.1186/s12944-019-1086-4. [PubMed: 31208420].

30. Chen R, Yan J, Liu P, Wang Z. Effects of thiazolidinedione therapy on inflammatory markers of type 2 diabetes: a metaanalysis of randomized controlled trials. PLoS One. 2015; 10(4):e0123703. doi: 10.1371/journal.pone.0123703. [PubMed: 25897968].

31. Park JS, Cho MH, Nam JS, Yoo JS, Ahn CW, Cha BS, et al. Effect of pioglitazone on serum concentrations of osteoprotegerin in patients with type 2 diabetes mellitus. Eur J Endocrinol. 2011;164(1):69-74. doi: 10.1530/EJE-10-0875. [PubMed: 20961967].

32. Kim NH, Kim DL, Kim KJ, Kim NH, Choi KM, Baik SH, et al. Effects of vildagliptin or pioglitazone on glycemic variability and oxidative stress in patients with type 2 diabetes inadequately controlled with metformin monotherapy: a 16-week, randomised, open label, pilot study. Endocrinol Metab. 2017;32(2):241-7. doi: 10.3803/EnM.2017.32.2.241. [PubMed: 28685513].

33. Khan S, Khan S, Panda BP, Akhtar M, Najmi AK. Potential effects of vildagliptin on biomarkers associated with prothrombosis in diabetes mellitus. Expert Opin Ther Targets. 2015;19(12):1607-16. doi: 10.1517/14728222.2016.1086338. [PubMed: 26357866].

34. Pfützner A, Marx N, Lübben G, Langenfeld M, Walcher D, Konrad T, et al. Improvement of cardiovascular risk markers by pioglitazone is independent from glycemic control: results from the pioneer study. J Am Coll Cardiol. 2005;45(12):192531. doi: 10.1016/j.jacc.2005.03.041. [PubMed: 15963388] 
35. Derosa G, Cicero AF, Gaddi A, Ragonesi PD, Piccinni MN, Fogari $\mathrm{E}$, et al. A comparison of the effects of pioglitazone and rosiglitazone combined with glimepiride on prothrombotic state in type 2 diabetic patients with the metabolic syndrome. Diabetes Res Clin Pract. 2005;69(1):5-13. doi: 10.1016/j.diabres.2004.10.007. [PubMed: 15955382]. 